\title{
DO MITO À RAZĀO: A LÓGICA DA AMBIGUIDADE E A LÓGICA DA NÃO CONTRADIÇÃO
}

\author{
Claudia Luiza Caimi ${ }^{1}$
}

claudiacaimi@furg.br

RESUMO: Este texto propōe a discussāo do lugar da imaginação e do lúdico na formação do saber. Apresenta o discurso filosófico grego como a origem do pensamento racional ocidental, que se constitui a partir da oposição com o pensamento veiculado no discurso mito-poético. Caracteriza o discurso da razāo a partir de uma lógica da não contradiçāo e o discurso mito-poético constituído por uma lógica da ambiguidade. Também é evidenciada a continuidade dessa divisāo no pensamento do séc. XVII, a partir da afirmaçāo da confiança em uma razāo que se funda na lógica causal e opositiva, contraposta por Vico, através da caracterizaçāo do pensamento poético, que apresenta uma lógica da semelhança, em que a analogia e repetiçāo constituem os universais poéticos. O saber produzido pelo pensamento mito-poético acolhe a experiencia e as possibilidades de produzir conhecimento oferecidas pela abertura à pluralidade, à alteridade e ao descentramento da subjetividade.

Palavras-chave: imaginaçāo; ludismo; razão; mimese; saber

O lúdico e o imaginário perderam o valor cognoscitivo e o caráter de construções de conhecimento formativo e transformativo que os antigos lhes atribuiam, em que confluiam individuo e História. Sāo hoje associados com irrealidade, ficçāo, fantasia, sonho, todas características pejorativas no

1 Professora da Universidade Federal de Rio Grande, RS 
âmbito do conhecimento e do social. A imaginação e o lúdico ainda são valorizados nos primeiros anos de escolarização, enquanto "o conhecimento" ainda não se configura em forma de conteúdo e disciplinas. Não é a ludicidade e o caráter imaginativo inerente a formas de conhecimento, mas a do informe psicológico infantil, ou seja, é uma questão de capacidade e desenvolvimento psicológico, como se, posteriormente, essas capacidades fossem perdidas, não mais fizessem parte da capacidade cognitiva do homem. Ou, também, como se o conhecimento fosse algo que se estabelecesse somente no âmbito do abstrato, do lógico, do formal, da série, da enumeraçāo, ou seja, na perspectiva dessas categorias que sustentam uma dimensão mais metódica do saber.

O lúdico e o imaginário, como expressão de experiência plena, são excluídos do conhecimento. Porém, esta separação entre a experiência plena e o conhecimento dá-se ainda entre os gregos. Num período anterior ao pensamento filosófico, a imaginação era um medium do conhecimento, tinha assegurado um papel cognoscitivo, ao instituir uma narrativa verdadeira, que manifesta a ordem do mundo. Através do mito, o homem participava de uma unidade em que não havia a divisão entre sujeito e objeto, coisa e palavra, espaço e tempo. Neste discurso a distância entre o homem e o mundo é dissolvida na apreensão das coisas, dos seres e de si, que inscreve o homem - por participação e repetição - na realidade. Como ordem manifestada pela emergência da consciência, através da participação (animismo, totemismo, antropomorfização) as classificaçōes e as análises lógicas são efetuadas com o auxílio de concepçōes concretas, que adquirem um caráter simbólico sem perder sua concretude e, através da repetição, o equilíbrio entre concepção de mundo e normas de comportamento estabelece harmonia entre o social e o natural, na reafirmação do mesmo.

Detienne, em Os mestres da verdade na Grécia arcaica (1988), busca entender a passagem do mito à razão a partir do ponto de vista de Vernant de que há razão no mito. Sua 
tese é a de que o pensamento racional surge do mito e que contém resquícios de religião. Essa relação o autor identifica a partir da trajetória da palavra alétheia (verdade) que se apresenta como um testemunho na mutação de um pensamento mitico em um pensamento racional, pois é, ao mesmo tempo, potência religiosa e conceito filosófico, marcando entre eles afinidade essencial e ruptura radical. As afinidades se dão pelo tipo de homens que são: o rei da justiça, o poeta, o adivinho e o filósofo: todos privilegiados que têm a "verdade" por atributo. O filósofo toma o lugar dos poetas, magos e adivinhos e do rei da justiça, pretendendo revelar a verdade que é homóloga e antítese da verdade religiosa. Homóloga, porque contém a verdade; antítese, porque a verdade do pensamento filosófico não é da mesma natureza da verdade do discurso arcaico, estabelecendo a ruptura com o mesmo.

Segundo Detienne, no discurso arcaico, o verdadeiro está vinculado à enunciação - do poeta, do rei, do adivinho - que instauram o real no dito, ficando o receptor passivo diante da palavra eficaz que institui em ato e se faz potência, já que traz em si ação. A palavra poética é herdeira do mito; sua função, porém, é outra: está ligada à mnemosyne, deusa da memória, faculdade divina que permite ver o passado. Diferente do mundo moderno que compreende a memória como uma categoria psicológica, na Grécia arcaica, a memória é uma força social que permite ao povo saber quem é por pertencer a uma mesma história, assegurando a identidade da nação na recuperação de um passado que não pode ser esquecido. Assim, os poetas cantam as façanhas dos deuses e dos soberanos, celebrando-os e enaltecendo-os, fazendo lembrar o passado e, concomitantemente, podendo fazer esquecer o presente. A memória - neste contexto - não é o oposto do esquecimento, mas seu contraditório, sua negação.

Detienne (1988) argumenta que no pensamento religioso-poético, que antecede ao pensamento racional, a palavra alétheia (verdade) mantém com outras potências: léthe (esquecimento), peithó (persuasão) e apaté (engano) relações que 
determinam a natureza de sua significação. Observa o autor que, na poesia, como no pensamento religioso, a passagem de aléthea a lethé traduz-se em termos de semelhança, pois é estabelecida uma equivalência ou, ao menos, um tipo de participação entre os dois termos da comparação, tendendo a uma idéia fundada no jogo de semelhança dos contrários, de coisa dupla. Através da memória se constitui a verdade poética, mas memória e esquecimento estão ligados, já que a verdade do poeta é assertiva, não se opõe à mentira ou ao falso, mas ao esquecimento. Com lethé dá-se uma relação de contraste antitético e complementar, marcando uma ambiguidade pelo jogo do veridico e do enganoso, já que a verdade se reveste do engano e o verdadeiro nāo nega jamais o falso. Como o mundo divino/poético é profundamente ambiguo, no plano do engano (apaté) está a idéia de uma presença na ausência e, complementarmente, a de uma ausência na presença, estabelecendo uma lógica em que os contrários são complementares e na qual a ambiguidade constitui um mecanismo essencial.

Essa ambiguidade manifesta-se no próprio discurso poético que pode ser benéfico ou maléfico, como fica evidenciado na fala das musas em Hesiodo (1995) "Pastores agrestes, vis infâmias e ventres só, sabemos [Musas] muitas mentiras dizer simeis aos fatos e sabemos, se queremos, dar a ouvir revelações". E também no canto das sereias na Odisséia, que dizem, vem aqui, decantado Ulisses, ilustre glória dos Aqueus: detém tua nau, para escutares nossa voz. Jamais alguém por aqui passou em nau escura, que não ouvisse a voz de agradáveis sons que sai de nossos lábios; depois afasta-te maravilhado e conhecedor de muitas coisas, porque nós sabemos tudo quanto se, na extensa Tróade, Argivos e Troianos sofreram por vontade dos deuses, bem como o que acontece na nutricia terra. (p. 115), prometendo a Ulisses o conhecimento do passado, do presente e do futuro que é, ao mesmo tempo, o esquecimento de tudo, pois nenhum homem sobreviveu ao canto delas. A palavra poética reveste-se de encantamento 
que persuade como uma força sagrada, podendo enganar ou revelar verdades. Quando começa a se mostrar a inquietação de que o logos (palavra) pode enganar, surgem as primeiras reflexões sobre a potência da palavra sobre a realidade e sobre o outro.

Vernant (s/d) demonstrou que o pensamento físico dos milésios (Tales de Mileto) dá-se a partir das grandes oposições estabelecidas no pensamento religioso-poético (Hesíodo). $\mathrm{O}$ autor tenta desmistificar a idéia do surgimento da razão filosófica instaurada de forma milagrosa, mostrando que a razão se constitui dentro do pensamento histórico. Busca demonstrar que o pensamento mítico e poético se desdobra até a discussão sobre o ser em Parmênides. Ele registra as pesquisas de Cornford, demonstrando que a Filosofia já encontra um modelo de explicação para o mundo na Teogonia através da luta entre potências e sua especificidade se constitui em despersonalizar o mito, transformando as potências divinas primordiais em elementos naturais: fogo frio, seco e úmido ${ }^{2}$. Jaeger (2001), em seus estudos sobre o homem grego, mostra que a poesia grega apresenta um modelo de narrativa em que os acontecimentos nunca são apresentados numa simples sequência narrativa, pois são sempre apresentados os motivos e as causas das açōes ${ }^{3}$ característica essa do pensamento filosófico nascente. Outras caracteristicas que os primeiros filósofos vão tornar núcleo da filosofia clássica, como

$2 \quad($...) no dominio da filosofia. caracterizam o novo pensamento grego. (São. por um lado.) a rejeição, na explicação dos fenômenos, do sobrenatural e do maravilhoso: por outro, a ruptura, com a lógica da ambivalência, a procura. no discurso, de uma coerēncia interna, por uma definiç̧āo rigorosa dos conceitos, uma nitida delimitação dos planos do real, uma estrita observância do principio de identidade' (VERNANT, s/d, p. 372-4)

3 Auerbach, em Mimesis (Perspectiva. 1897) também apresenta o estilo homérico na narrativa grega como uniformemente objetivo. A singularidade deste estilo está em representar os fenòmenos acabadamente. palpáveis e visiveis em suas partes, definindo claramente as relações espaciais e temporais, diferente das narrativas biblicas que apresentam falta de conexão, efeito sugestivo, multiplicidade de planos entre outros. 
a idéia e o sentimento de moderaçāo e medida, têm origem na poesia lírica, e a idéia de justiça como virtude fundamental e condição para outras virtudes, conforme está no pensamento de Platão, é apresentada em Os trabalhos e os dias, de Hesiodo.

Para Vernant, o novo na filosofia é uma explicação que se destituiu da magia e do maravilhoso, despersonalizando os elementos e os deuses e rompendo com a lógica da ambivalência. A explicação filosófica institui um pensamento abstrato, que apresenta respostas contundentes e principios lógicos, que se aproximam da verdade por raciocinio que, por sua vez, distingue o ser (substância) e as qualidades. Assim, com Parmēnides (e depois radicalizado por Platão) alétheia se confunde com a exigência da não contradição. Nesse pensamento, os contrários são postos simultaneamente no plano da linguagem, de forma que a verdade se institui na e pela linguagem dialética, que tem como princípio o diálogo, duas vozes, e por fim a maiêutica, ponto único em que a verdade se coloca. A verdade é alcançada por pensamento lógico.

Essa transformação está ligada à existência de relações sociais igualitárias e estruturas politicas inéditas (democracia) que se estabelecem a partir do surgimento da cidade. Com o advento da cidade, diz Detienne (1988), a palavra atinge sua autonomia como instrumento político. Esta palavra laicizada, complementar à ação - autônoma e inscrita no tempo - surge do grupo social dos guerreiros, nas assembléias guerreiras e nos funerais, quando da partilha dos saques e da distribuição das oferendas. A palavra do guerreiro não é solitária e unilateral como a dos mestres da verdade arcaicos. é palavra-diálogo, pública. pois perante a assembléia todos os guerreiros têm o direito de emitir opinião, já que são iguais diante do grupo. fundamentando seu discurso no acordo do grupo que manifesta sua aprovaçāo ou desaprovação. A palavra-diálogo, apesar de se manifestar como uma opinião, doxa, tendo um caráter persuasivo, já que deve convencer os pares. é pública e necessita do acordo entre os homens para obter sua eficácia. 
Com Simônides de Céos, poeta grego que viveu no século IV a.C., Detienne e Vernant identificam a desvalorização da alétheia, já que é ele o primeiro poeta a fazer da poesia um ofício remunerado, cobrando para cantar as glórias de um soberano, rejeitando a concepção religiosa da poesia ao transformá-la em instrumento político e ilusório. Simônides descobre o caráter artificial da palavra poética, como imagem do real e não parte dele. Evidencia na palavra poética é a capacidade de ilusão, de fazer parecer quando não é.

Para Detienne, na formação do pensamento filosófico, a ambiguidade se distingue da alétheia e se refugia na doxa, que acolhe um conhecimento que vem do movimento do mundo, apresentando a possibilidade de uma escolha, e mais, de uma escolha que varia de acordo com a situação. É no àmbito da sofística que ela se estabelece, já que para os sofistas, a palavra está delimitada no campo da tensão de dois discursos sobre cada coisa, na contradição das duas teses, tornando lógico o ambiguo. Desse modo, o ambíguo não é mais a união dos contrários complementares, mas a sintese dos contrários contraditórios. A palavra, para o sofista, é um instrumento, mas não de conhecimento real. O logos é uma realidade em si, mas não é um significante que tende a um significado. No pensamento sofístico nāo há distância entre a palavra e as coisas, há puros exercícios de retórica em que, através de argumentação, defendem teses contrárias para convencer a favor de uma. Portanto, a sofistica, por um lado, representa o triunfo da palavra ambígua, por outro é responsável, através da prática dos discursos opostos e da análise dos modos do discurso, pela formação do princípio de identidade e pelo advento de uma lógica da exclusāo das proposições contrárias.

Por volta do século VI a.C., surge um tipo de pensamento filosófico religioso (os pitagóricos, Parmênides) que se opōe ao pensamento dos sofistas e renova a significação da alétheia. Para estes filósofos, por um lado, existe o imutável, o Ser, a memória, a alétheia, e, por outro, o fluente, o não ser, o esquecimento. Para Detienne, essa postura parece aproximar 
as seitas filosóficas dos poetas e adivinhos, mas enquanto nos poetas a alétheia é inseparável de peithó (engano), nas seitas é radicalmente separada dela. Seu universo espiritual é um mundo dicotômico onde a ambiguidade cedeu lugar à contradição e o homem acha-se lançado num universo dualista de oposiçōes nitidas no qual a escolha se impōe.

Nesse sistema de pensamento que se separa da lógica do mito, alétheia se torna uma potência mais definida e mais abstratamente concebida: simboliza um plano do real que toma a forma de uma realidade intemporal que se afirma como ser imutável e estável e se opõe radicalmente a um outro plano de realidade que o tempo, a morte e a lethé definem. No entanto, ainda que a ambiguidade tenha desaparecido como zona intermediária entre termos antitéticos, não foi riscada do mundo humano, como forma do real. Foi afastada do conhecimento, que vai ser, pela primeira vez, tratado em Platão, a partir de uma consciente necessidade de afastar um tipo de educaçāo para a constituição de outro.

Todo o desenvolvimento do pensamento inaugurado pelos pré-socráticos está ligado à separação da palavra do dominio da ação. Na palavra laica, a ação é inscrita no tempo e distinta do discurso. O discurso como realidade autônoma é encerrado em suas próprias leis: conformidade com os princípios lógicos e com o real, submetendo-se à necessidade de referenciar sua verdade. Havelock (1996) defende a tese de que grande parte da obra de Platão é um feroz ataque à poesia como uma disciplina educativa do homem grego, como repositório de conhecimentos úteis, espécie de enciclopédia de ética, política, história e tecnologia que os cidadãos ativos aprendiam como essência de seu preparo educacional e como um modo conservado de comunicação oral. que estabelecia uma consciência, um vocabulário e uma sintaxe, através de uma tecnologia verbal disponivel através da fala ritmica. Essa forma de educação e instruçāo instaura-se num estado (psicológico) de completo envolvimento pessoal de identificação emotiva com o enunciado. A memória oral conservada carac- 
teriza-se, para Havelock, por identificação e repetição; atitudes que não exigem nem objetividade, nem análise.

Platão define no Teeteto (1986) - como verdadeiro conhecimento - a ciência: sistema de opiniōes verdadeiras travadas pela razão dialética, que se mostra mais estável porque encadeia (através da lógica) as opiniōes verdadeiras e possibilita uma ascensão segura do mundo do relativo para o mundo do absoluto. Tanto a sofistica quanto a poesia, por utilizarem a persuasão e não a demonstração, são incapazes de alcançar o verdadeiro conhecimento. Este implica organizar, dominar e avaliar dados fora do pensamento, já que a filosofia platônica, ao postular a existência da psyque e desenvolver uma distinção do eu para o que não é o eu (existência do sujeito), acabou por supor a existencia do objeto. Assim, quando se pensa, pensa-se sobre alguma coisa.

Havelock diz que Platão quer estabelecer uma nova forma de pensar a partir da abstração, separando e isolando principios e constituindo conceitos, em uma linguagem cuja sintaxe é analítica, que não visa à identificação; antes, a expressão. Para separar o eu, é necessário abandonar o ato e o evento (tempo, espaço, circunstância) e pensar nas coisasem-si. Para tal, o múltiplo é transformado em uno a partir de um ato de integração que nega a vivência dos acontecimentos e oferece uma abstração em que nada acontece, apenas é. Assim isoladas, as coisas não são apenas um; também são ser no sentido em que sua expressão linguistica é isenta de tempo verbal (uso do infinitivo) e, portanto, de duração. $O$ objeto abstrato, divorciado da ação concreta deve perder também a visibilidade, pois a experiência visual de cor e forma ocorre apenas quando a essência do objeto é multiplicada e tornada especifica. A essência (o Ser, as Idéias) é então abstrata, una e fixa e constitui um sistema de integração total de hierarquias ascendentes e descendentes que formam uma lógica interna própria.

Não cabe aqui discutir a leitura que Havelock faz da obra de Platão, já que é acolhida a proposição de que a poesia 
mostra-se como um arsenal da cultura grega, como uma fonte de informação, um sistema de doutrinação e como o modelo de educação. Porém é importante registrar que Platão é muito mais complexo, pois condenou a escrita pela escrita e dissociou-se da mimese mimeticamente, ao utilizar recursos da poesia como o diálogo mimético (dramatização), enquanto expressão da oralidade e reprodução da voz, presentes em quase toda a sua obra, mas mais bem trabalhados no Fedro e no Banquete e a narrativa ficcional, enquanto verossimilhança, elaborada no Timeu e nos vários mitos que narra em sua obra.

Mas é a proposição platônica do conhecimento, enquanto pensamento sobre a experiência e da distância em vez da identificação, exposta por Havelock, que permanece na tradição educacional ocidental. A exclusão da lógica da ambiguidade completa seu curso em Platão e vamos ver em Aristóteles uma sintaxe discursiva abstrata, um sistema filosófico classificatório e uma teoria do conhecimento desvinculada da experiência e da história.

Um outro momento decisivo da separação entre conhecimento e experiência dá-se com o nascimento da ciência moderna. O pensamento científico inicia na modernidade com Galileu e Copérnico, que começam a revolução da Física, tornando-a a ciência explicativa do real, que se desenvolve, graças à Matemática, por dedução e experienciação. Mas é Descartes quem alia o saber físico-matemático com uma concepção de real em uma teoria do conhecimento que se pergunta pela natureza do sujeito cognoscente e pela natureza do objeto conhecido. O sujeito cognoscente de Descartes é eu penso, que concebe a si próprio a partir da dúvida hiperbólica: levando o limite máximo da dúvida sobre tudo, mas que - ao extremá-la - evidencia a certeza traduzida na possibilidade de duvidar. Para tal é preciso pensar e, consequentemente, "se penso: existo" O sujeito cartesiano é puro pensamento, capaz de fazer abstrações do sensivel, tornando-o inteligivel. Neste sentido, o objeto do conhecimento se constitui a partir da evidência intelectual, marcada pela 
clareza e distinção, apreendida pela via da intuição, pois a visão intelectual - voltada para um campo preparado e ordenado pelo método e autorizada e garantida pela luz inata da razão - instaura a certeza da existēncia de si e o critério de verdade e garantia do conhecimento ${ }^{4}$

Porém, para chegar à máxima de que a única fonte de verdade é o pensamento, Descartes libertou-se da natureza e da tradição, estabelecendo uma dicotomia entre Epistemologia e História. O sujeito do conhecimento foi privado das paixões e das certezas da autoridade e da tradição e o objeto do conhecimento foi destituido dos padrões coletivos de cultura e História. Descartes rompe radicalmente com a cultura da curiosidade e do espanto, destituindo do conhecimento o maravilhoso, o oculto, o mistério, o enigma, o desejo, e os sentidos ao só admitir a ação lúcida da razāo metódica.

Com Descartes, a experiência é mais uma vez excluída do conhecimento, que busca "idéias claras e distintas" pois ela se apresenta incompativel com a certeza. O pensamento autônomo, seguro e indubitável afasta-se da tradiçāo, das certezas subjetivas das paixões, dos desejos, das emoções, das fantasias e toda a variabilidade e particularidade decorrentes da contingência e da arbitrariedade. De forma que,

Assim, porque os nossos sentidos nos enganam às vezes. quis supor que não havia coisa alguma que fosse tal como eles nos fazem imaginar. E, porque há homens que se equivocam ao raciocinar. mesmo no tocante às mais simples materias de geometria, e cometem ai paralogismos, rejeitei como falsa. julgando que estava sujeito a falhar como qualquer outro, todas as razōes que eu tomara até então por demonstraçōes. E enfim. considerando que todos os mesmos pensamentos que temos quando despertos nos podem também ocorrer quando dormimos, sem que haja nenhum. nesse caso. que seja verdadeiro, resolvi fazer de conta que todas as coisas que até então haviam entrado no meu espirito nāo eram mais verdadeiras que as ilusões de meus sonhos. Mas, logo em seguida, adverti que. enquanto eu queria assim pensar que tudo era falso, cumpria necessariamente que eu, que pensava. fosse alguma coisa. E, notando que esta verdade: eu penso. logo existo, era tão firme e tão certa que todas as mais extravagantes suposiçōes dos céticos nāo seriam capazes de a abalar. julguei que podia aceitá-la, sem escrúpulo, como o primeiro principio da filosofia que procurava. (DESCARTES, Discurso do Método. quarta parte) 
para Descartes, entre o res cogitans e res extensa a fantasia e a imaginação não são necessárias, pois não há necessidade de nenhuma mediação para o ato de inteligência ${ }^{5}$

A experiência é substituída pelo experimento, sendo que, no lugar da autoridade (da tradição e da ação) coloca-se a certificação; neste sentido, a ciēncia moderna propõe um sujeito do conhecimento que reúne em si as propriedades do intelecto separado do sujeito da experiência, como uma realidade psíquica substancial e autônoma. Ela desprezou e desqualificou como conhecimento ou saber verdadeiro o que não podia ser quantificado e objetivado. E a escola, que surge neste cenário, se solidifica, confiando na descrição quantitativa do mundo, na demonstração estatística, nas generalizaçōes, na reprodutividade experimental e na fé do poder da razāo.

O surgimento do pensamento filosófico entre os gregos e do científico na modernidade foram marcos da opção por um conhecimento que se estabelece na confiança em uma razão que se funda numa lógica causal e opositiva. Essa, porém, apesar de ter sido acolhida para sustentar a formação escolar, não gozou de absoluta unanimidade. Desde Platão, mesmo tendo expulsado os poetas da Polis, a lógica da semelhança atormenta o pensamento. Essa lógica, presente no pensamento mito-poético, acata os contrários como complementares (DETIENNE, 1988), como sombra, deslocando-se progressivamente ao outro reciproco. Esse pensamento obedece a uma lógica de contrariedades, no qual a ambivalência constitui um mecanismo essencial. Desta forma, a lógica da semelhança acata o jogo, o paradoxo, o instável, a indeterminação, todos esses conceitos que hoje estão presentes na

5 La certificación científica de la experiencia efectúa en el experimento - que permite deducir las impresiones sensibles con la exactitud de determinaciones cuantitativas y por ende prever impresiones futuras - responde a esa pérdida de certeza que desplaza la experiencia lo más afuera posible del hombre: a los instrumentos y a los números. Pero de este modo la experiencia tradicional perdia en realidad todo valor. (AGAMBEN, 2004, p. 14) 
maioria dos pensadores contemporâneos, nas várias áreas do conhecimento, mas que a escola ainda não acolheu no processo de formação.

Trazer a lógica da semelhança para o conhecimento foi o empreendimento de Vico na Ciência Nova. Para Vico a natureza humana não é imutável. No ato de conhecer os homens transformam-se a si mesmos e ao mundo. Daí a razão não possuir um núcleo central, uma essência que permaneça idêntica a si mesma, como propunha Descartes.

Segundo Vico, a teoria do conhecimento formulada por Descartes, orientando-se exclusivamente pelo conhecimento matemático, subordina todas as demais esferas da indagação à esfera da razão abstrata, e essa pretensão racionalista do cartesianismo se constitui utópica, pois existem certezas humanas fundamentais que, como a retórica, a prudência, a poesia, as leis, as instituições as obras de arte, os rituais, e outras que regulam a vida prática, não se baseiam em verdades do tipo matemático, mas sobre o verossímil ${ }^{6}$.

O argumento de Vico é o de que só se pode conhecer o feito, já que a verdade e o fato são a mesma coisa. A verdade só pode ser encontrada no domínio de tudo aquilo que o homem fez ou produz, naquilo que é expressão da vontade humana e não na natureza, como é pretensão do cartesianismo, pois não há como o homem conhecer a causa de seu próprio ser porque ele não é essa causa, não criou a si mesmo. Neste sentido, as proposições matemáticas satisfazem ao critério da auto-evidência porque a matemática é um sistema produzido pelo homem a partir de necessidades da ação humana na busca de satisfazer a realização de objetivos e/ou desejos.

6 Este mundo civil foi certamente feito pelos homens, cujos principios podem. porque devem. ser descobertos dentro das modificaçōes de nossa própria mente humana. A bem refletir sobre tal fato, causa estranheza (verificar) como todos os filósofos seriamente estudaram o modo de obter a ciència deste mundo natural, do qual - pois que Deus o fez - somente ele tem ciência: e deixaram de meditar este mundo das naçōes, ou seja, o mundo civil. do qual - pois o fizeram os homens - podiam obter sua ciência os homens. (VICO, 1999. p. 131 -2) 
A ciência nova tem como método penetrar os principios e as causas dentro do curso das naçōes, recolhendo a ordem que flui de elementos e formas de vida que nem sāo fortuitas, nem determinadas, mas dirigidas e destinadas a satisfazer necessidades, desejos e ambições. Neste sentido, as produçōes culturais podem ser entendidas, interpretadas e avaliadas a partir da compreensão do propósito para o qual foram criadas $^{7}$

Na investigação do desenvolvimento da humanidade. Vico empreende uma volta aos modos de compreensão das coisas, dos sentimentos e das atitudes das comunidades humanas primitivas. Resulta deste processo uma história universal que se constituiu por três estágios (ou idades), cada qual correspondendo a uma forma de organização social, política e jurídica. Na Idade dos Deuses, os homens que fundaram a sociedade humana eram néscios, insensatos e horriveis bestas, sem nenhum poder de reflexão, mas dotados de sentidos agudos e poderosa fantasia. Diante das forças naturais que os ameaçavam, sentiam e imaginavam divindades terriveis e castigadoras e, por temor a estas divindades, começaram a refrear os instintos, criando familias e as primeiras ordens civis. Vico chama-as de repúblicas monásticas, pois criam regras de convivência baseadas em rituais religiosos e acreditam viver sob governo direto dos deuses. A linguagem é muda, feita de gestos, sinais e caracteres. Na Idade dos Heróis, as famílias se unem, formando a aristocracia, que domina o restante da população em governos oligárquicos. Cria-se o direi-

\footnotetext{
Observamos que todas as naçōes bárbaras humanas, ainda que. por imensos intervalos de espaços e tempos entre si distanciadas. guardaram estes três humanos costumes: todas possuem alguma religiāo, todas contraem matrimónios solenes, todas sepultam seus mortos (...) Pois. pela dignidade de que idéias uniformes, principiadas junto à totalidade dos povos. não conhecidos entre si. devem ter um motivo comum de verdade. deve ter sido ditada a todas: dessas três coisas. começou a humanidade e. por isso. devem ser preservadas (...). Para isso tomamos esses trés costumes eternos e universais corno os três principios desta Ciência. (VICO, 1999, p. 132)
} 
to baseado na religião. Fundam-se as cidades, que cultivam as virtudes heróicas da piedade, da prudencia, da moderação, da fortaleza e da magnanimidade. Os homens derivam sua nobreza dos deuses e a fantasia ainda prevalece sobre a reflexão. O modo de expressão dessa vida é a linguagem simbólica, repleta de imagens e metáforas, não existindo fronteiras entre a imaginação e a realidade, como se pode observar na poesia de Homero. Na Idade dos homens, o governo assume a forma de república popular ou de monarquia, ambas assegurando a igualdade de direitos para todos os cidadãos livres. O homem passa a explicar o universo mediante a metafísica raciocinada e a relação com uma ordem providencial toma a forma de reflexāo que procura rastrear a idéia de bem, sobre a qual os homens devem estar de acordo. A linguagem se baseia em vocábulos convencionados.

Essa visão histórica é, ao mesmo tempo, progressiva e cíclica. De um lado progressista, porque de uma fase bestial passa para uma fase heróica e depois racional, por outro lado é cíclica, porque as três fases marcam um ciclo, que eternamente reinicia, formando uma espiral. Com essa lógica, Vico assegura a continuidade entre fantasia e razão, ambas fazendo parte de um processo mais amplo de investigação de mundo incompletamente conhecido.

Como a História dá a tópica do repertório dos possiveis já realizados, dentre as muitas produções humanas, Vico distingue a linguagem como o subsistema simbólico e normativo que imprime em si as formas de vida e da experiência. Assim, é no mergulho nas formas de linguagem da humanidade que ele especifica o material para outras possibilidades de conhecer para além das categorias tradicionais do dedutivo a priori e do empírico a posteriori.

Vico diferencia a linguagem mito-poética da linguagem silogistica. A linguagem mito-poética anima toda a natureza mediante o emprego da semelhança. que se constitui por analogias, primitivamente através de antropomorfização e depois por metaforização, e por ludismo, reprodução das constantes 
que adquirem possibilidade e levam ao deleite. Esta linguagem, como a silogistica, também apresenta um princípio classificador. Mas enquanto a linguagem silogística forma os universais lógicos a partir dos princípios da identidade, da não contradição e do terceiro excluído, a linguagem mito-poética forma os gêneros inteligiveis das coisas em universais poéticos: deuses, heróis, ritos, entre outros, a partir da analogia e do ludismo, respectivamente, compreendidos pelo autor como participação e repetição ${ }^{8}$

Para Vico, o pensamento fantástico - veiculado pela linguagem mito-poética - que no princípio fingiu os mitos e depois se aloja nas imagens, nas formas das coisas que a fantasia muda, separa e compōe, vincula-se com a experiência social guardada na memória. Assim, a analogia e a imaginação reconstrutiva são métodos de conhecimento, já que a fantasia tem o poder de modelar as imagens das coisas, gerando novas formas sendo, portanto, criadora. O lúdico, por sua vez, revela o prazer que o homem sente ao constituir o uniforme, formando constantes. São as coisas verossímeis que possibilitam e regulam a vida prática e não a razão abstrata.

A defesa de Vico a outras formas de conhecimento, como sabemos, não teve êxito no século XVIII, século em que a grande maioria dos pensadores acatou o argumento socrático e racionalista do imaginário/tradição/lúdico/opinião como o outro (contrário) da razão. Nas palavras de Foucault, o rompimento desse movimento dá-se com os "mestres da suspeita: Marx, Freud e Nietzsche" (FOUCAULT, s/d) e, depois, com seus seguidores, apontando para a ideologia, o inconsciente $\mathrm{e}$ o caráter metafórico da linguagem e, consequentemente, co-

8 Os homens primeiramente sentem sem perceberem: a seguir percebem com o espirito perturbado e comovido, e, finalmente, refletem com mente pura. Esse aforismo é o principio das sentenças poéticas, que sảo formadas com sentidos de paixōes e de afetos, diferentemente das sentenças filosóficas, que constituem pela reflexão e mediante raciocinios. Por isso estas marcham vigorosamente para a verdade, quanto mais se alçam para os universais: e aquelas. tanto mais acertadas resultam quanto mais se apropriam dos particulares. (VICO, 1988, p. 152). 
locando em questão a razão fundamentada numa metafisica da verdade. O que não impediu que a racionalidade instrumental e mercantil se estendesse por nosso tempo e se estabelecesse na formação escolar.

\section{Conclusāo}

Resgatar o movimento da vida humana na sua plena possibilidade para o universo do conhecimento consiste em acolher uma proposiçāo de verdade para além do propósito de dominar uma realidade conflitiva pela coerência, homogeneização e regras imutáveis e eternas. O caráter descontinuo e contraditório da realidade - e múltiplo do objeto - exigem um pensamento capaz de respeitar e elaborar a pluralidade e a ambivalência na forma de um conhecimento que se constitua como uma exercício de ressignificação infinita do mundo, que não pode nunca ser totalmente conhecido, só reinscrito.

Assim, colocar em questão os padrões do conhecimento e acolher possibilidades do pensável, como as geradas pela lógica da semelhança, provocam e evocam a disponibilidade do saber. Neste sentido, o lúdico e o imaginário, capazes de abrigar a ambiguidade, o reinício e o imprevisivel, se mostram elementos importantes na formulação de novas possibilidades de conhecer que abrigam a experiência, pensada como um estar intensivo no mundo. A lógica da semelhança manifesta essa pluralidade incessante que se abre constantemente a outra coisa impredizivel e incalculável.

Vico não coloca a semelhança como o outro da razão, num movimento de valorização do irracionalismo, em que o mito surgiria como a única verdade revelada. Ele apresenta a fantasia rememorativa como um método de conhecimento ao lado do racionalismo lógico, mais adequado à compreensão do fenômeno histórico e, portanto, humano. Ao evidenciar as semelhanças e o comportamento mimético como possibilidades de conhecimento. Vico possibilita que pensemos a imagi- 
nação e o ludismo como dimensōes de um modo de conhecer que resgata nāo só a vida prática, mas também possibilidades de experiência para a formaçāo escolar, que proponham a essa uma dimensão ética e estética. Estética, no sentido oferecido por Wolfgang Iser, de um acolhimento do jogo, daquilo que "está sempre associado a alguma coisa outra que o si mesmo. (ISER, W. 2001), provocadora de uma ética aberta à pluralidade, ao descentramento da subjetividade e à alteridade, pois proporciona uma formaçāo na qual se dá, como diz Larrosa, principalmente "um deformar e um transformar a maneira como nomeamos o que vemos e vemos o que nomeamos" (LAROSSA, 2004, p. 272).

\section{BibLIOGRAFIA:}

AGAMBEN, Giorgio. Infancia e historia: destruccion de la experiência y origen de la historia. Trad. Silvio Mattoni, Buenos Aires: Adriana Hidalgo editora, 2004.

BOBBIO, Norberto. "Vico" In A teoria das formas de governo. Brasilia: UNB, 1988.

BOSI, Alfredo. "Leitura de Vico" In O ser e o tempo na poesia. São Paulo: Cultrix, 1977.

DEBORD. Guy. A sociedade do espetáculo. Rio de Janeiro: Contraponto, 1997

DESCARTES, René. Discurso do Método, Meditaçōes, Objeçōes e respostas, As paixōes da alma, cartas. São Paulo: Abril cultural, 1979. (Os pensadores).

DETIENNE, Marcel. Os mestres da verdade na Grécia antiga. Rio de Janeiro: Zahar, 1988.

ECO. Umberto. Apocalípticos e integrados. São Paulo: Perspectiva, 1970. FOUCAULT, Michel. Nietzsche, Freud e Marx, Theatrum Philosoficum. Porto: Rés, s/d.

JAEGER, Werner. Paidéia: a formaçāo do homem grego. Sāo Paulo: Martins Fontes, 2001.

GADAMER, Hans-Georg. Verdad y método. Salamanca: Ediciones Sigueme, 1988.

HAVELOCK, Eric. Prefácio a Platāo. Campinas, SP: Papirus, 1996. 
HESÍODO. Teogonia: a origem dos deuses. São Paulo: Iluminuras, 1995. HOMERO. Odisséia. Trad. Antônio Pinto Carvalho. São Paulo: Abril Cultural, 1981.

ISER, Wolfgang. O ressurgimento da estética. In: ROSENFIELD, Denis (org). Ética e estética. Rio de Janeiro: Zahar, 2001.

LARROSA, Jorge. La experiência de la lectura: estúdios sobre literatura y formación. Barcelona: Laertes, 1996.

. Linguagem e Educação depois de Babel. Belo Horizonte: Autêntica, 2004.

PLATĀO. Obras completas. Madrid: Aguilar, 1986.

VERNANT, Jean-Pierre. Mito e Pensamento entre os gregos: estudos de psicologia histórica. São Paulo: Paz e Terra. s/d.

VICO, Giambattista. Principios de uma ciència nova: acerca da natureza comum das nações. São Paulo: Nova cultural, 1988. (Os pensadores) A ciència Nova. Traduçāo, prefácio e notas de Marco Lucchesi, Rio de Janeiro: Record, 1999.

ABSTRACT: This work aims at discussing the role of imagination and playfulness in the formation of knowledge. It presents the Greek philosophic discourse as the origin of western rational thought, which is established from its opposition to the thought carried by the mythicalpoetic discourse. It characterizes the reason discourse based on the logic of no-contradiction, and the mythical-poetic discourse constituted by the logic of ambiguity. It also demonstrates the continuity of that division in the $17^{\text {th }}$ century's thought by the trust in a reason founded on the logic of cause and opposition, contradicted by Vico, through the characterization of poetic thought, which presents the logic of similarity and in which analogy and repetition constitute the poetic universals. Knowledge produced by mythical-poetic thought accepts experience and the possibilities of producing knowledge fostered by the opening for plurality, otherness and discentering of subjectivity.

Keywords: Imagination; playfulness; reason; mimesis; knowledge 